\title{
Reactivity of anti-thyroid antibodies to thyroglobulin tryptic fragments: comparison of autoimmune and non-autoimmune thyroid diseases
}

L.H.B. Boechat and R.L. Zollner

\author{
Laboratório de Imunologia Clínica, Faculdade de Ciências Médicas, \\ Universidade Estadual de Campinas, Campinas, SP, Brasil
}

\section{Correspondence}

R.L. Zollner

Laboratório de Imunologia Clínica

Departamento de Clínica Médica

FCM, UNICAMP

Caixa Postal 6111

13081-970 Campinas, SP

Brasil

E-mail: zollner@obelix.unicamp.br

Research supported by CN Pq

(No. 132405/94-6). L.H.B. Boechat was the recipient of a $\mathrm{CN} \mathrm{Pq}$

fellowship. Publication

supported by FAPESP.

\section{Abstract}

Studies concerning the antigenicity of thyroglobulin fragments allow the characterization of the epitopes but do not consider the role of heavier antigenic fragments that could result in vivo from the action of endoproteases. Here we assess the relative importance of the fragments obtained from thyroglobulin by limited proteolysis with trypsin and compare by immunoblotting their reactivity to serum from patients with autoimmune (Graves' disease and Hashimoto's thyroiditis) and non-autoimmune (subacute thyroiditis) disease. The results showed no difference in frequency of recognition of any peptide by sera from patients with autoimmune thyroiditis. In contrast, sera from patients with subacute thyroiditis reacted more frequently with a peptide of 80 $\mathrm{kDa}$. These results suggest the presence of antibody subpopulations directed at fragments produced in vivo by enzymatic cleavage of thyroglobulin. This fragment and antibodies to it may represent markers for subacute thyroiditis.

\section{Introduction}

Thyroglobulin is a protein of $660 \mathrm{kDa}$ and the main product of thyroid follicular cells. Hormone liberation from this heavy precursor depends on its proteolysis at predetermined sites in an organized fashion (1). Endopeptidases such as cathepsin D and cysteine-proteases such as cathepsin B, H and L have been implicated in this process and their synergistic action seems to be necessary for hormone secretion $(2,3)$.

Studies trying to determine the sites of proteolytic action and correlate them with the tertiary structure of thyroglobulin have demonstrated the presence of areas sensitive to proteolysis located at the C-terminal end and especially in peptide sequences inserted among blocks of internal homology. Gentile et al. (4) have proposed that human thyroglobulin could be spontaneously broken between residues 503 (leucine) and 505 (serine), located between the fourth and fifth blocks of type 1 homology. These regions are also susceptible to trypsin, thermolysin and cathepsins B, D and L (1-3).

Trypsin does not participate physiologically in thyroglobulin production, but its ac- 
tivity at low enzyme/substrate ratios is analogous to that of thyroid endoproteases, leading to the production of peptides similar to those derived from lysosomal processing of this prohormone. Although many investigators have tried to determine the relationship between thyroglobulin structure and the immune system, reports concerning the reactivity of peptides obtained from the action of endoproteases in vivo are not frequent in the literature. Thus, analysis of the immunogenic characteristics and protein sequence of these thyroglobulin fragments can help understand the origin and role of antithyroglobulin antibodies in autoimmune and nonautoimmune thyroid diseases. Moreover, the study of thyroglobulin antigenicity can provide new data for the understanding of the involvement of thyroglobulin as an autoantigen in autoimmune and non-autoimmune thyroid diseases.

The aim of the present study was to evaluate the reactivity of the peptide panel obtained by limited trypsin hydrolysis of thyroglobulin. Sera from patients with autoimmune thyroid disease and subacute thyroiditis were reacted with the fragments, in order to identify possible differences between these disorders.

\section{Material and Methods}

\section{Patients and sera}

Sera from patients with Graves' disease (5), Hashimoto's thyroiditis (5) and subacute thyroiditis (6) were studied. The diagnosis of Graves' disease was made on the basis of clinical findings of thyrotoxicosis, diffuse goiter and ophthalmopathy and confirmed by detection of high free thyroxin and reduced levels of thyrotropin (TSH) (Baxter Diagnostics Inc., Deerfield, IL, USA). Hashimoto's thyroiditis was diagnosed by clinical findings of hypothyroidism associated with high levels of TSH and low free thyroxin. For both diseases, an autoimmune origin was suggested by the elevation of antithyroglobulin or antithyroperoxidase antibodies. Diagnosis of subacute thyroiditis was based on findings of cervical pain irradiating to ear and jaw, accompanied by asthenia and fever. The presence of a high erythrocyte sedimentation rate, low radioiodine uptake during scintigraphy, and giant multinucleate cells in thyroid aspirates was also considered for the diagnosis. All blood samples were obtained during the first visit to the hospital when none of the patients was receiving anti-thyroid drugs. Patients presenting other autoimmune or infectious diseases were excluded from the study. The mean levels of anti-thyroglobulin antibodies were $872 \pm 344.3 \mathrm{IU} / \mathrm{ml}$ in patients with Hashimoto's thyroiditis and $1235 \pm 369.9$ $\mathrm{IU} / \mathrm{ml}(\mathrm{P}=0.478)$ in patients with Graves' disease when tested by radioimmunoassay (Serono Diagnostics, Norwell, MA, USA). Sera from patients with subacute thyroiditis did not present detectable antibodies by this method. Sera from five healthy individuals were used as negative controls.

\section{Thyroglobulin preparation}

Normal thyroid tissue was obtained from a patient undergoing laryngectomy associated with hemi-thyroidectomy due to larynx carcinoma. Immediately after removal, the thyroid was washed in phosphate-buffered saline (PBS), pH 7.3, carefully dissected, cut into small fragments and homogenized in a blender. After filtration and centrifugation at $2000 \mathrm{~g}$ for $20 \mathrm{~min}$, the pellet was discarded and the soluble material dialyzed against PBS for $24 \mathrm{~h}$. All procedures were carried out at $4^{\circ} \mathrm{C}$ in the presence of protease inhibitors $(1 \mathrm{M} \mathrm{NaCl}, 50 \mathrm{mM}$ Tris- $\mathrm{HCl}, 1 \mathrm{mM}$ phenyl-methyl-sulfonyl fluoride, $20 \mathrm{mM}$ EDTA, and $50 \mathrm{mM} \varepsilon$-amine caproic acid, $\mathrm{pH}$ 7.5). The thyroid homogenate was submitted to Sephadex G-200 (Pharmacia Fine Chemicals, Uppsala, Sweden) gel filtration at $9 \mathrm{ml} /$ $\mathrm{h}$, with the void volume corresponding to 
human thyroglobulin. This was confirmed by SDS-PAGE, immunoblotting and radioimmunoassay (Diagnostic Products Co., Los Angeles, CA, USA).

\section{Limited trypsinization of thyroglobulin}

Human thyroglobulin was dialyzed against $50 \mathrm{mM}$ Tris- $\mathrm{HCl}$ and $130 \mathrm{mM} \mathrm{NaCl}$, $\mathrm{pH} \mathrm{8.4,} \mathrm{and} \mathrm{its} \mathrm{concentration} \mathrm{was} \mathrm{adjusted} \mathrm{to}$ $2 \mathrm{mg} / \mathrm{ml}$ by dilution in the same buffer. Thyroglobulin was then submitted to trypsin hydrolysis (Trypsin type III, Sigma Chemical Co., St. Louis, MO, USA) for $60 \mathrm{~min}$ at $30^{\circ} \mathrm{C}$ at an enzyme/substrate ratio $(\mathrm{w} / \mathrm{w})$ of $1 / 1000$. Tryptic digestion was stopped by dilution in SDS-PAGE sample buffer $(62.5$ $\mathrm{mM}$ Tris- $\mathrm{HCl}, 10 \%$ glycerol and $0.001 \%$ bromophenol blue) and boiling for $90 \mathrm{~s}$ in the presence of $10 \%(\mathrm{v} / \mathrm{v}) 2$-mercaptoethanol (Sigma Chemical Co.).

\section{SDS-PAGE}

Electrophoresis was performed on a vertical slab by the method of Laemmli (7) at room temperature. When appropriate, the disulfide bridges of the samples were reduced by adding $10 \%(\mathrm{v} / \mathrm{v}) 2$-mercaptoethanol followed by boiling for $2 \mathrm{~min}$. The gels were stained with $0.2 \%$ Coomassie brilliant blue R 250 by the usual methods.

\section{Immunoblotting}

Thyroglobulin or its fragments were transferred electrophoretically to a nitrocellulose membrane (Trans-Blot Transfer Medium, 0.45 micron; Bio-Rad, Hercules, CA, USA) at $4^{\circ} \mathrm{C}$ as described by Towbin (8). Nonspecific reactions were blocked with $3 \%$ fetal calf serum, $0.3 \%$ gelatin, and $0.05 \%$ Tween 20 for $1 \mathrm{~h}$. Nitrocellulose was washed in PBS and then incubated with patient sera diluted 1:1000 for $3 \mathrm{~h}$. After a second cycle of washing, the membrane was incubated with peroxidase-conjugated goat anti-human IgG for $1 \mathrm{~h}$ in the dark. Membranes were stained with 3,3'diaminobenzidine (DAB, Sigma Chemical Co.) in $\mathrm{H}_{2} \mathrm{O}_{2}$ as described by De Blas and Cherwinski (9).

\section{Statistics}

The frequency of positive reaction of each tryptic fragment with sera from the groups studied was compared by the $\chi^{2}$ test with Yates correction or, when indicated, by the Fisher exact test, with the level of significance set at $\mathrm{P}<0.05$.

\section{Results}

\section{Thyroglobulin preparation and limited trypsin hydrolysis}

The crude thyroid extract contained 4.4 $\mathrm{mg} / \mathrm{ml}$ protein and showed bands ranging from about $300 \mathrm{kDa}$ to $15 \mathrm{kDa}$ when analyzed by SDS-PAGE. After filtration through a Sephadex G-200, the initial peak corresponding to the void volume of the column was identified as thyroglobulin by SDSPAGE on the basis of immunoblotting and radioimmunoassay (Figure 1). After limited proteolysis, thyroglobulin was degraded to peptides with molecular masses ranging from 205 to fragments smaller than $29 \mathrm{kDa}$, as shown in Figure 2.
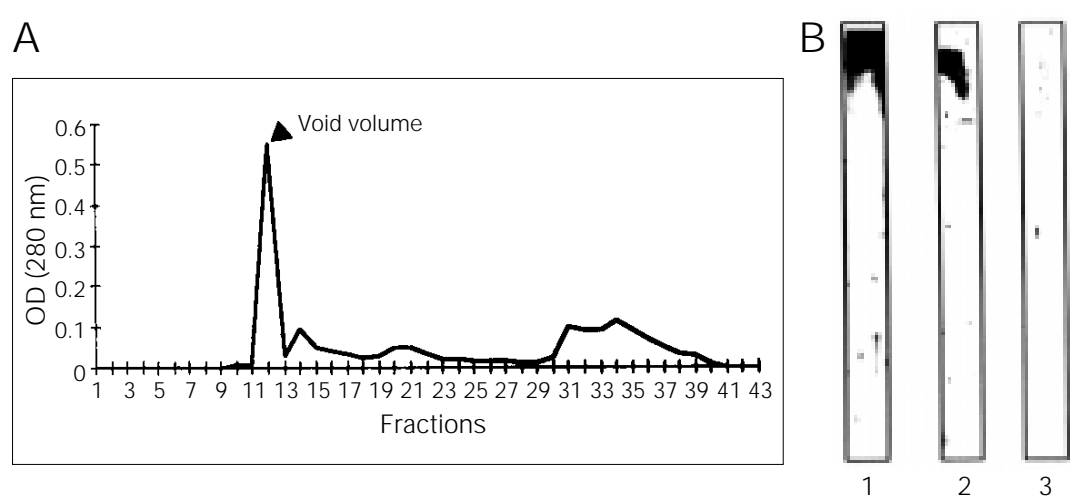

Figure 1 - Preparation of thyroglobulin. A, Gel filtration on Sephadex G-200 of an extract of human thyroid. Thyroglobulin was eluted in the void volume. B, SDS-PAGE of void volume effluent. Lane 1, Silver-stained; lane 2, detected with anti-thyroglobulin antibodies; lane 3, not detected with anti-TPO antibodies. 
Figure 2 - SDS-PAGE of thyroglobulin and fragments obtained by limited trypsin hydrolysis. The samples contained $10 \mu \mathrm{g}$ protein which was heat denatured in the presence of 2-mercaptoethanol. Protein was detected with Coomassie blue staining. Lane 1 , Crude extract of thyroid tissue; lane 2, thyroglobulin purified by gel filtration (Figure 1A); lane 3 , limited trypsin hydrolysate of thyroglobulin.

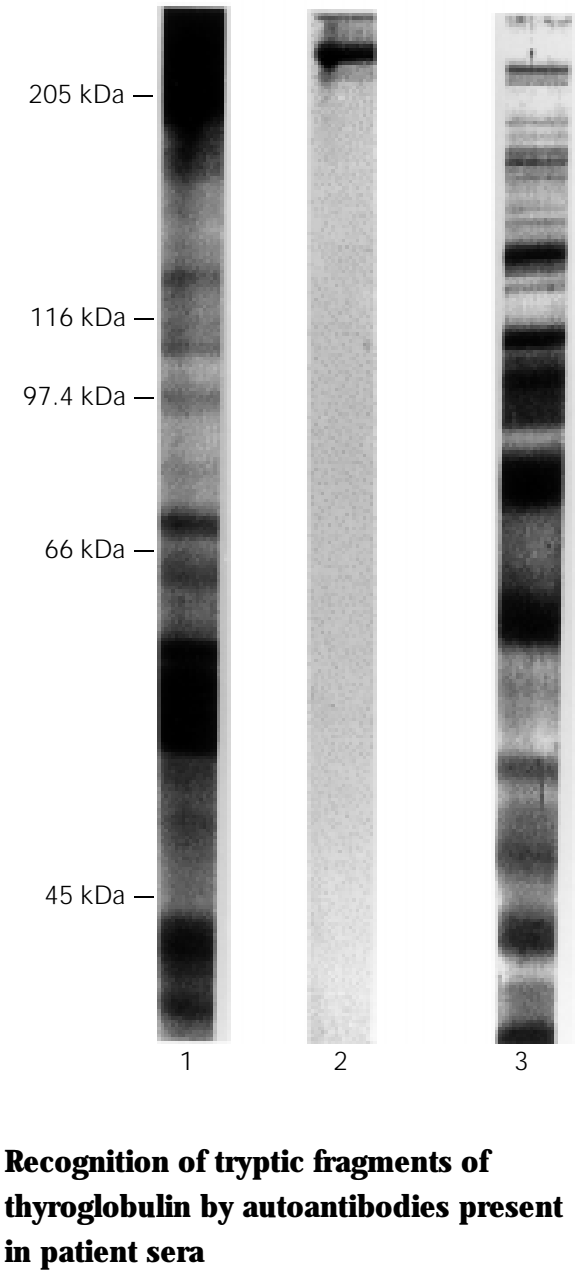

Only peptides with molecular masses above $45 \mathrm{kDa}$ were recognized (Figure 3). There was no significant difference in the recognition of any peptide by sera from patients with Graves' disease or Hashimoto's thyroiditis. Thus, these data were grouped for comparison with patients presenting subacute thyroiditis. Peptides with molecular masses of 80,185 and $>205 \mathrm{kDa}$ reacted more frequently with sera from patients with subacute thyroiditis than with those presenting autoimmune thyroid disease (Table 1).

\section{Discussion}

Although thyroglobulin has been studied for decades, it was only after the report of its structure (10) that advances in the under- standing of its behavior as an autoantigen became possible. Its high molecular mass (2748 amino acids) impairs the production of recombinant thyroglobulin, and therefore studies on the whole monomer are performed with protein material obtained from human or animal glands. Many experimental methods have been used, including acid precipitation $(6,11)$ and chromatographic fractionation (12). In the present study, we decided to use the latter approach, since it excludes potential risks of structural modifications produced by exposing the protein to $\mathrm{pH}$ levels outside the physiological range (13). It was possible to obtain human thyroglobulin with a high level of purity, as confirmed by SDS-PAGE, immunoblotting and radioimmunoassay analysis.

Thyroid hormone synthesis includes the capture of iodinated thyroglobulin from the follicular lumen and its processing by endoproteases, finally leading to $T_{4}$ and $T_{3}$ synthesis in late endosomes (14). This seems to be a controlled process and cathepsins B, $\mathrm{D}, \mathrm{H}$ and $\mathrm{L}$ are the best known enzymes whose proteolytic action could produce fragments with conserved antigenic characteristics. Gentile and Salvatore (1) used the method of limited proteolysis, with low enzyme/substrate ratios and variable times of reaction to determine the preferential sites of action of trypsin and thermolysin. Comparing their results with those of Dunn et al. $(2,3)$, it can be seen that these enzymes cleave thyroglobulin at sites of action similar to those of cathepsins.

In the present study, we performed limited thyroglobulin proteolysis with an enzyme/substrate ratio of $1 / 1000$, since these conditions permitted us to obtain peptides ranging from $<29$ to $>205 \mathrm{kDa}$. Our results are comparable to those of Gentile and Salvatore (1) who described peptides of human thyroglobulin of 265, 230, 145, 105, 80, 56 and $29 \mathrm{kDa}$. However, we have also observed other fragments with molecular masses close to these. This may have been 
due to differences in the trypsin preparations used, since in our case some residual chymotrypsin action was probably present.

Many investigators have published data concerning the antigenicity of thyroglobulin fragments. However, these studies generally focus on small synthetic peptides or on those obtained by proteolysis with higher enzyme/ substrate ratios and for longer periods of time (15). These approaches allow the characterization of epitopes but do not consider the role of heavier antigenic fragments that could result, in vivo, from the action of endoproteases. Our findings suggest that antithyroglobulin antibodies recognize many antigenic sites in thyroglobulin, since immunoblotting reactions were positive for all peptides above $45 \mathrm{kDa}$. The inability to recognize smaller fragments could be related to spatial changes and loss of conformational epitopes.

There was no difference in frequency of recognition of any peptide by sera from patients with Graves' disease and Hashimoto's thyroiditis and therefore these data were pooled into a single group concerning autoimmune thyroid disease. In contrast, sera from patients with subacute thyroiditis reacted more frequently with peptides of 80 , 185 and $>205 \mathrm{kDa}$.

The action of trypsin on residue 522 of thyroglobulin produced fragments of 80 and $265 \mathrm{kDa}$. This hydrolysis site, located between the fourth and fifth area of internal homology type 1 , is also susceptible to hydrolysis by thermolysin and cathepsin B and $\mathrm{L}$, and also is an area of spontaneous cleavage of thyroglobulin $(1,2,4)$. On this basis, the $80-\mathrm{kDa}$ fragment may correspond to the first 521 amino acids of the amino-terminus containing the hormonogenic site at tyrosine 5 and four of the ten areas of internal homology type 1 . These characteristics suggest a fragment with a rigid structure and probably able to preserve conformational epitopes.

Epitope mapping of thyroglobulin indicates the existence of at least 11 antigenic

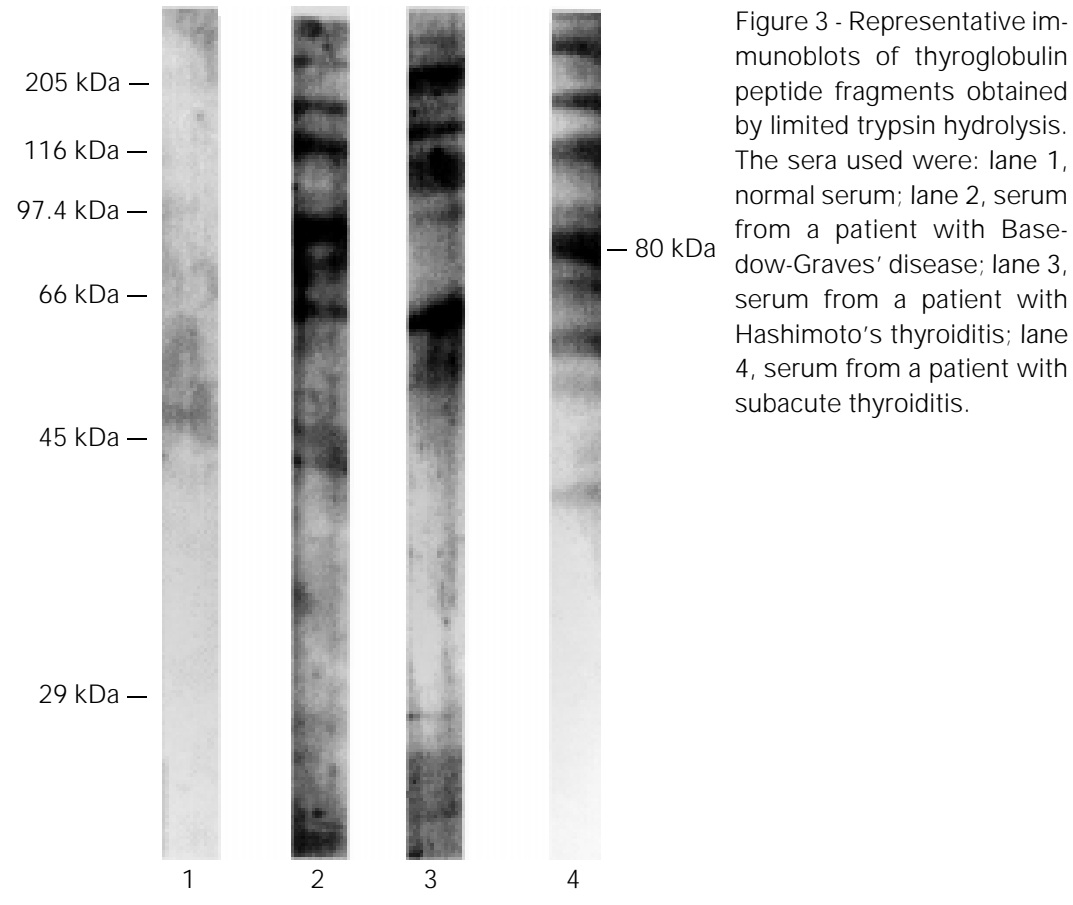

Table 1 - Absolute and relative frequencies of reactivity of anti-thyroglobulin antibody with tryptic fragments of human thyroglobulin in patients with autoimmune thyroid disease and subacute thyroiditis.

ap $=0.0400 ; \mathrm{bP}=0.0230 ; \mathrm{cP}=0.0233$ all compared to subacute thyroiditis $\left(\chi^{2}\right.$ test).

\begin{tabular}{ccc}
\hline Fragments $(\mathrm{kDa})$ & Autoimmune thyroid disease & Subacute thyroiditis \\
\hline$>205$ & $17 / 36(47.2 \%)^{\mathrm{a}}$ & $9 / 10(90 \%)$ \\
185 & $12 / 36(33.3 \%)^{\mathrm{b}}$ & $8 / 10(80 \%)$ \\
170 & $4 / 36(11.1 \%)$ & $0 / 10(0 \%)$ \\
160 & $4 / 36(11.1 \%)$ & $4 / 10(40 \%)$ \\
145 & $18 / 36(50.0 \%)$ & $6 / 10(60 \%)$ \\
130 & $11 / 36(30.5 \%)$ & $2 / 10(20 \%)$ \\
115 & $12 / 36(33.3 \%)$ & $3 / 10(30 \%)$ \\
110 & $16 / 36(44.4 \%)$ & $7 / 10(70 \%)$ \\
100 & $9 / 36(25.0 \%)$ & $6 / 10(60 \%)$ \\
90 & $17 / 36(47.2 \%)$ & $5 / 10(50 \%)$ \\
80 & $9 / 36(25.0 \%)^{c}$ & $7 / 10(70 \%)$ \\
75 & $8 / 36(22.2 \%)$ & $5 / 10(50 \%)$ \\
70 & $10 / 36(27.7 \%)$ & $0 / 10(0 \%)$ \\
66 & $10 / 36(27.7 \%)$ & $1 / 10(10 \%)$ \\
60 & $13 / 36(36.1 \%)$ & $4 / 10(40 \%)$ \\
56 & $11 / 36(30.5 \%)$ & $1 / 10(10 \%)$ \\
50 & $2 / 36(5.5 \%)$ & $1 / 10(10 \%)$ \\
45 & $5 / 36(13.8 \%)$ & $0 / 10(0 \%)$ \\
& &
\end{tabular}


areas mainly located in the central region, but also comprising the $\mathrm{C}$ - and $\mathrm{N}$-terminal ends $(16)$. Henry et al. $(17,18)$ proposed that antithyroglobulin autoantibodies from patients with autoimmune thyroid diseases are related to epitopes in the central and Cterminal areas. Bouanani et al. (5) published data indicating differences in the pattern of antigen recognition between healthy subjects and patients with autoimmune diseases. Similarly, Ruf et al. (19) proposed that the repertoire of thyroglobulin autoantibodies is the same in healthy individuals and in patients with autoimmune diseases or thyroid carcinoma, with differences only in the frequency of epitope commitment. Based on these facts, they suggested that different mechanisms could be responsible for the elevation of antithyroglobulin antibody titers in these situations, namely disorders of immunoregulation in thyroid autoimmune diseases and antigen liberation associated with polyclonal activation in carcinomas.

In subacute thyroiditis, follicles are disrupted and large amounts of thyroglobulin and thyroid hormones are released into the blood (20). This is probably associated with viral infection, where many defense mechanisms are activated. Polyclonal activation occurs in response to some viral infections, mainly through the action of superantigens (21). Thus, circulating thyroglobulin or its fragments may result in the amplification of antithyroglobulin antibodies, in this case directed at epitopes exposed on the surface and not necessarily related to immunodominant regions. The reactivity of serum from subacute thyroiditis patients to fragments of thyroglobulin and not to the whole molecule (present in commercial kits) suggests hidden antigenic epitopes and should be further in- vestigated to determine whether this event reflects a "physiological" or an "autoimmune" disturbance.

Data obtained from models of experimental autoimmune thyroiditis show that thyroglobulin peptides are able to induce the amplification of antithyroglobulin antibodies, especially when administered in combination with polyclonal activators such as Freund's adjuvant. These peptides, obtained by proteolysis or synthesized in the laboratory, are normally localized in central or Cterminal areas of thyroglobulin (22-24). Information about experimental thyroiditis induced by N-terminal sequences is not common in the literature. The more frequent reaction to the peptide of $80 \mathrm{kDa}$ in patients with subacute thyroiditis does not indicate a pathogenic role but rather seems to represent an epiphenomenon, since follicular destruction and cell death probably release not only thyroglobulin, but also endoproteases and peptides produced by their action. Many authors have reported the development of Hashimoto's thyroiditis after subacute thyroiditis (25-28). It would be interesting to determine the repertoire of antithyroglobulin antibodies in these patients in order to elucidate some of the immune mechanisms involved or to identify a subtype of antithyroglobulin antibody.

\section{Acknowledgments}

The authors gratefully acknowledge Mrs. Conceição Aparecida Vilella for technical assistance and Dr. Denise Zantut E. Wittmann, Discipline of Endocrinology, and Dr. Mario J.A. Saad for a critical reading of the manuscript. 


\section{References}

1. Gentile F \& Salvatore G (1993). Preferential sites of proteolytic cleavage of bovine, human and rat thyroglobulin. The use of limited proteolysis to detect solvent-exposed regions of the primary structure. European J ournal of Biochemistry, 218: 603-621.

2. Dunn AD, Crutchfield HE \& DunnJ (1991). Proteolytic processing of thyroglobulin by extracts of thyroid lysosomes. Endocrinology, 128: 3073-3080.

3. Dunn AD, Crutchfield HE \& DunnJ (1991). Thyroglobulin processing by thyroid proteases. Major sites of cleavage by cathepsins B, D and L. Journal of Biological Chemistry, 266: 20198-20204.

4. Gentile F, Palumbo G \& Salvatore G (1992). The origin of the electrophoretic doublet of thyroglobulin. Biochemical and Biophysical Research Communications, 186: 1185-1191.

5. Bouanani M, Hanin V, Bastide M \& Pau B (1992). New antigenic clusters on human thyroglobulin defined by an expanded panel of monoclonal antibodies. Immunology Letters, 32: 259-264.

6. Lemansky P \& Herzog V (1992). Endocytosis of thyroglobulin is not mediated by mannose-6-phosphate receptors in thyrocytes. European J ournal of Biochemistry, 209: 111-119.

7. Laemmli UK (1970). Cleavage of structural proteins during the assembly of the head of bacteriophage T4. Nature, 227: 680-685.

8. Towbin H, Staehelin T \& Gordon J (1979). Electrophoretic transfer of proteins from polyacrylamide gels to nitrocellulose sheets and some applications. Proceedings of the National Academy of Sciences, USA, 76: 4350-4354.

9. De Blas AL \& Cherwinski HM (1983). Detection of autoantigens on nitrocellulose paper immunoblots with monoclonal antibodies. Analytical Biochemistry, 133: 214219.

10. Malthièry $Y \&$ Lissitzky S (1987). Primary structure of thyroglobulin deduced from the sequence of its 8448-base complementary DNA. European J ournal of Biochemistry, 165: 491-498.

11. Gruffat D, Venot N, Marriq C \& Chabaud O (1992). Thyroid hormone synthesis in thyroglobulin secreted by porcine thyroid cells cultured on porous bottom chambers: effect of iodide. Endocrinology, 131: 2921-2927.

12. Chan CTJ, Byfield RL, Himsworth RL \& Shepherd P (1987). Human autoantibodies to thyroglobulin are directed towards a restricted number of specific epitopes. Clinical and Experimental Immunology, 69: 516-523.

13. Edelhoch $H$ (1960). The properties of thyroglobulin: the effects of alkali. J ournal of Biological Chemistry, 235: 1326-1334.

14. Rousset B (1991). Traffic intracellulaire et clivage protéolytique de la thyroglobuline, la prohormone thyroïdienne. Annales d'Endocrinologie, 52: 355-360.

15. Salamero J, Remy J J, Michel-Bechet MM \& Charreire J (1987). Experimental autoimmune thyroiditis induced by a 5-10 $\mathrm{kDa}$ tryptic fragment from porcine thyroglobulin. European J ournal of Immunology, 17: 843-848.

16. Malthièry $Y$, Henry $M \&$ \&anelli E (1991). Epitope mapping of the human thyroglobulin reveals a central immunodominant region. FEBS Letters, 279: 190-192.

17. Henry M, Zanelli E, Piechaczyk M, Pau B $\&$ Malthièry $Y$ (1992). A major human thyroglobulin epitope defined with monoclonal antibodies is mainly recognized by human autoantibodies. European J ournal of Immunology, 22: 315-319.

18. Henry M, Malthièry $Y$, Zanelli $E \&$ Charvet B (1990). Epitope mapping of human thyroglobulin: heterogeneous recognition by thyroid pathologic sera. J ournal of Immunology, 145: 3692-3698.

19. Ruf J , Carayon P \& Lissitzky S (1995). Various expressions of a unique anti-human thyroglobulin antibody repertoire in normal state and autoimmune disease. European J ournal of Immunology, 15: 268-272.

20. Volpé R (1986). Autoimmune thyroiditis. In: Ingbar SH \& Braverman LE (Editors), The Thyroid. A Fundamental and Clinical Text. J B Lippincott Co., Philadelphia.

21. Miethke $T$, Wahl $C$, Heeg $K K \&$ Wagner $H$ (1995). Superantigens: the paradox T-cell activation versus inactivation. International Archives of Allergy and Immunology, 106: 3-7.

22. Chronopoulou E \& Carayanniotis G (1992). Identification of a thyroiditogenic sequence within the thyroglobulin molecule. J ournal of Immunology, 149: 1039-1044.

23. Hutchings PR, Cooke A, Dawe K, Champion BR, Geysen M, Valerio R \& Roitt IM (1992). A thyroxin-containing peptide can induce murine experimental autoimmune thyroiditis. J ournal of Experimental Medicine, 175: 869-872.

24. Texier B, Bèdin C, Tang H, Camoin L, Laurent-Winter C \& Charreire J (1992). Characterization and sequencing of a 40amino acid peptide from human thyroglobulin inducing experimental autoimmune thyroiditis. J ournal of Immunology, 148: 3405-3411.

25. Ivy HK (1961). Permanent myxedema: an unusual complication of granulomatous thyroiditis. J ournal of Clinical Endocrinology and Metabolism, 21: 1384-1389.

26. Tikkanen MJ \& Lamberg BA (1982). Hypothyroidism following subacute thyroiditis. Acta Endocrinologyca, 101: 348-353.

27. Marinoni U \& Marinoni P (1984). Evoluzione, a lunga distanza, della tiroide acuta e subacuta. Giornale di Clinica Medica, 65 : 433-439.

28. Gozariu L, Stroe M, Vladutiu T, YepezEscobar G, Simiones CO, Szantay E, Dumitru E \& Florescu O (1986). Late hypothyroidism following subacute thyroiditis. Experimental and Clinical Endocrinology, 87: 48-52. 